\title{
Predictive Method for Chemical Structure Changing of Turbine Oil
}

\begin{abstract}
LIANA BOGATU, BOGDAN DOICIN*, ION ONUTU
Universitatea Petrol -Gaze Ploiesti, 39 Bucuresti Blvd., 100520, Ploiesti, Romania

Lubricants are influenced over their lifetimes by various factors such as temperature, oxygen, water contamination, etc. which affect the chemical structure and implicitly their specific characteristics. If the degradation of the oils is significant and the characteristic values exceed certain limits that are defined for the safe operation, the lubricants should be replaced. The main purpose of the present study is to offer an efficient and predictive method for an adequate quality control of lubricant oils in service and implicitly for their adequate and safe operation. The method developed in this study consists in a numerical algorithm (the multiple regression) and is based on the monitoring of lubricant oils' representative characteristics in time and allows estimating the evolution of the oils characteristics during the service period as well as the prediction of the life-time of the oils.
\end{abstract}

Keywords: chemical structure degradation, quality control, oils monitoring, prediction, mathematical algorithm

It is very well known that the turbine machines and equipment used for producing energy are characterized by high capacity and need large quantities of lubricant oils. The specific benchmark of oil for a typical turbine is 10,000 liters $[1,2]$.

These significant large volumes of turbine oils presume high financial efforts, so an important requirement of this type of oil is an extended lifetime which implicitly assumes a high chemical structure stability and high level of quality.

The turbine oils are characterized by a suitable viscosity and viscosity index, high flash point and low pour point, a very good capability of water separation (demulsibility), good protection to corrosion and rust, proper anti-wear capacity, very good oxidation resistance (high stability of the chemical structure to oxidation) and high capability of air separation (air-release and foam tendency/stability).

Typical characteristics of the turbine oils that are stated by the turbine equipment manufacture engineers are specified by various quality standards of the turbine oils manufacturers. A summary of the representative characteristics, within these standards, is presented in the table no.1 (by average features), for the most usual viscosity class of turbine oils: ISO-VG 32, ISO-VG 46, ISO-VG 68 [3$6]$.

The quality requirements for this kind of lubricants are very exigent and, for achieving all them, the turbine oils must be manufactured from selected deep refined base oils and effective additives.

Considering the severe conditions of turbine oils applications, especially in terms of extent lifetime, another very important item in the operation of these oils, is the ensuring of a very careful maintenance and the monitoring of their behavior in service [7-10].

These procedures may prevent the occurrence of adverse events in the turbine operation and offer the possibility to identify, in a due time, any potential or concrete problems during the service period of turbine oils.

The quality control and the proper maintenance of the oils are made by checking the specific values of the representative characteristics, periodically, at well planned interval of time [11].

\begin{tabular}{|c|c|c|c|c|}
\hline Characteristic & ISO-VG 32 & ISO-VG 46 & ISO-VG 68 & Test Method \\
\hline Density at $15^{\circ} \mathrm{C}, \max$ & 0.895 & 0.895 & 0.895 & ASTM D 1217 \\
\hline Viscosity at $40^{\circ} \mathrm{C}, \mathrm{cSt}$ & $28.8-35.2$ & $28.8-35.2$ & $61.2-74.8$ & ASTM D445 \\
\hline Viscosity Index, min. & 90 & 90 & 90 & ASTM D 2270 \\
\hline Flash point, ${ }^{\circ} \mathrm{C}$, min. & 200 & 200 & 210 & ASTM D 92 \\
\hline Pour point, ${ }^{\circ} \mathrm{C}, \max$. & -20 & -20 & -15 & ASTMD 97 \\
\hline Demulsibility, minutes & 30 & 30 & 30 & ASTM D 1401 \\
\hline Copper corrosion & $1 \mathrm{~b}$ & $1 \mathrm{~b}$ & $1 \mathrm{~b}$ & ASTM D 130 \\
\hline Rust prevention & pass & pass & pass & ASTM D 665 \\
\hline $\begin{array}{l}\text { 4-Ball Test: scar diameter } \\
(20 \mathrm{daN}, 100 \mathrm{~min}) \mathrm{mm}, \max .\end{array}$ & 0.4 & 0.4 & 0.4 & ASTM D 4172 \\
\hline Rotary Bomb, minute, min & 300 & 300 & 300 & ASTM D 272 \\
\hline $\begin{array}{l}\text { Foam Tendency/Stability, at: } \\
-24^{\circ} \mathrm{C}, \mathrm{ml} / \mathrm{ml}, \max . \\
-93.5^{\circ} \mathrm{C} \mathrm{ml} / \mathrm{ml}, \max . \\
-24^{\circ} \mathrm{C} \mathrm{ml} / \mathrm{ml}, \max .\end{array}$ & $\begin{array}{l}100 / 0 \\
50 / 0 \\
100 / 0\end{array}$ & $\begin{array}{l}100 / 0 \\
50 / 0 \\
100 / 0\end{array}$ & $\begin{array}{l}150 / 0 \\
100 / 0 \\
150 / 0\end{array}$ & ASTM D 892 \\
\hline
\end{tabular}

Table 1

REPRESENTATIVE CHARACTERISTICS OF TURBINE OILS[3-6] 
During the lifetime of the oil, its quality deteriorates. The lubricants quality degradation could have many sources and causes: degradation of the oil chemical structure due of the temperature, oxygen presence, contamination, accidental mixing with another type of lubricant, contamination with dust or water etc. [12, 13].

The oxidation is the most important phenomenon, responsible for the oil degradation and itaffects many other representative characteristics like: viscosity, acidity, flammability, foam tendency and stability, demulsibility, cleanness etc.

All these characteristics undergo changes during the lifetime of the lubricants and, when they exceed certain set limits, jeopardize the proper functioning of the lubricant. Therefore, in order to have accurate and representative information about the quality stage of the oils during its use, those chemical and physical characteristics which have a significant impact on the oil behavior are periodically tested, in conformity with an adequate laboratory testing scheme that highlights their evolution [12-14].

Given the real importance of the lubricant's quality monitoring as well as the prevention of the potential malfunctions in a due time, the main purpose of this study was to determine a relevant and effective method for assessing the quality of the lubricants in service. Based on the proposed method, it is possible to prevent potential damages to equipment in a timely manner and this is particularly useful for large capacity equipment that requires large amounts of lubricants, as the turbine equipment $[15,16]$.

The designed method, starting from the experimental testing of the turbine oils characteristics, is the regression analysis. The regression analysis is a mathematical modeling technique which is used to correlate two or more lubricant properties. The main use of the obtained model is to predict how many months are left before a lubricant change is required, because its properties fell below the acceptable limits.

In this paper, a mathematical model referring to the life of the oil (months) was conceived using the regression based on the evolution over time of two relevant characteristics, oxidation resistance and foaming tendency and also on the admissibility limits stated for these characteristics [17].

\section{Experimental part}

The turbine oils monitoring program was implemented for four turbine equipment that are in service on a high capacity power plant; the turbine oils quality was identical for all four equipment (supplied by the same producer), were working in similar lubricating conditions, for a period of 38 month.

The program for the complete characterization of turbine oils is generally based on a high number of analyses. Usually, the modification of the lubricant quality in time is evaluated by testing of the following characteristic: kinematic viscosity, water and sediment content, oxidation resistance, foaming properties, acidity index, flash point.

For the present study that aimed to use the regression method as monitoring technique, two representative features of program were selected for providing relevant information on chemical structure and behavior of turbine oils: oxidation resistance and foam tendency. The selection of these characteristics was based on literature data and previous experimental performed studies.

A summary description of the characteristics importance as well as specific testing methods used for their study is presented further.
Oxidation resistance of oils gives information about their capacity to keep undamaged the chemical structure of the components. Oxidation of oil is responsible for the occurring of acid components as well as for the heavy component structures; this phenomenon has undesirable consequence on the oil service conditions, generating increasing of the compressibility, affecting the effective pressure of the system, worsen the heat transfer and the lubrication capability of the oil $[8,12]$. Therefore, the measuring of the oil oxidation in time is an important task for the oil quality monitoring.

Capacity of oil oxidation resistance can be assessed by various testing methods, some considered fast, which have a shorter test time, and others with an extended duration testing.

In the present study Rotary bomb test method (ASTM D 2272) was used; that is a relatively fast method, with a quite high degree of accuracy, allowing a proper assessment of oxidation resistance [18].

Foaming properties are expressed by two features: tendency and stability of the oil foam. The foaming phenomenon can generate serious problems in the lubrication systems of turbine oils, as well as for the highspeed gearing oils, hydraulic pumps oils, engine oils etc. Inadequate lubrication regime, cavitation effects and overflow loss of lubrication could lead to mechanical failure. The foaming could be caused by different chemical polar compounds, by dirt, by water etc.

Foam properties of the turbine oils were tested in conformity with ASTM D 892 standard method. This test covers the determination of the foaming characteristics of lubricating oils at $24^{\circ} \mathrm{C}$ and $93.5^{\circ} \mathrm{C}$ [18].

As has been previously shown, in order to assess the oils behavior during their life time, it has been necessary the monitoring of these features over an extended period, under concrete working conditions. Therefore, the experiments were conducted in parallel, on four turbines, during a significant long period of time (38 months).

To obtain accurate and relevant information, oil samples have been collected according to a very rigorous procedure: the oils samples were representative, taken from key points of the lubricating system, collected in clean vessels, in conditions of system operation.

The experimental results, the evolution of the features and related comments are presented further.

\section{Results and discussions}

All the turbine oil samples have been tested according to the monitoring program. In this respect, the oil samples collected each month for all the four turbines were analyzed by testing oxidation resistance, foam tendency and other representative characteristics.

Considering that the mathematical model for turbine oils monitoring was conceived using the regression based on the evolution of oxidation resistance and foaming tendency over time, and these testing results for those characteristics are presented in Tables 2 and 3.

As could be seen from the evaluation of the testing results, the values of the turbine oils characteristics, for all the four turbines, were very similar. In order to represent more conclusive the behavior of the oils during the 38month period, a graphical representation, based on the average values of the monthly tested characteristics, is shown in the Figure 1, that specifically represents the variation of the oxidation resistance and foaming tendency in time.

For this collaborative study, multiple regression was chosen to develop an appropriate method to predict the lifetime of turbine oils. The proposed mathematical model 
Table 2

EVOLUTION OF THE OXIDATION RESISTANCE ALONG OF 38 MONTHS PERIOD

\begin{tabular}{|c|c|c|c|c|}
\hline \multirow{2}{*}{ Month } & \multicolumn{4}{|c|}{ Oxidation Resistance, ASTM D 2272, minutes } \\
\hline & Turbine 1 & Turbine: & Turbine 3 & Turbine 4 \\
\hline 1 & 520 & 510 & 525 & 530 \\
\hline 2 & 520 & 510 & 510 & 525 \\
\hline 3 & 520 & 510 & 520 & 530 \\
\hline 4 & 520 & 510 & 520 & 525 \\
\hline 5 & 515 & 510 & 515 & 520 \\
\hline 6 & 515 & 510 & 515 & 520 \\
\hline 7 & 515 & 515 & 515 & 515 \\
\hline 8 & 515 & 510 & 510 & 515 \\
\hline 9 & 515 & 510 & 510 & 515 \\
\hline 10 & 515 & 510 & 515 & 515 \\
\hline 11 & 510 & 510 & 510 & 515 \\
\hline 12 & 500 & 500 & 510 & 515 \\
\hline 13 & 500 & 500 & 510 & 510 \\
\hline 14 & 500 & 490 & 500 & 505 \\
\hline 15 & 490 & 480 & 490 & 500 \\
\hline 16 & 480 & 475 & 475 & 480 \\
\hline 17 & 475 & 470 & 470 & 480 \\
\hline 18 & 470 & 460 & 465 & 475 \\
\hline 19 & 460 & 450 & 460 & 470 \\
\hline 20 & 450 & 445 & 450 & 460 \\
\hline 21 & 445 & 440 & 445 & 450 \\
\hline 22 & 430 & 425 & 435 & 440 \\
\hline 23 & 430 & 425 & 430 & 435 \\
\hline 24 & 420 & 420 & 420 & 430 \\
\hline 25 & 410 & 400 & 415 & 420 \\
\hline 26 & 395 & 390 & 400 & 400 \\
\hline 27 & 380 & 375 & 375 & 380 \\
\hline 28 & 370 & 360 & 365 & 370 \\
\hline 29 & 345 & 340 & 345 & 350 \\
\hline 30 & 315 & 310 & 315 & 315 \\
\hline 31 & 290 & 275 & 280 & 290 \\
\hline 32 & 270 & 260 & 265 & 265 \\
\hline 33 & 250 & 240 & 245 & 250 \\
\hline 34 & 225 & 220 & 225 & 225 \\
\hline 35 & 200 & 195 & 200 & 210 \\
\hline 36 & 160 & 160 & 160 & 160 \\
\hline 37 & 120 & 120 & 120 & 120 \\
\hline 38 & 60 & 60 & 60 & 60 \\
\hline
\end{tabular}

usea, as presentea apove, the two monitored characteristics of the turbine oils, oxidation resistance and foaming tendency, as independent variables and the time, as dependent variable.

Other important references in the mathematical model are the limits of admissibility for the chosen characteristics, that means those values of the characteristics, up to which the oil works safely.

These specific values of the limits of admissibility are very clearly stated, due of their importance for the appropriate and safe operation of the oils and cannot be exceeded.
Table 3

EVOLUTION OF THE FOAM TENDENCY ALONG OF 38 MONTHS PERIOD

\begin{tabular}{|c|c|c|c|c|}
\hline \multirow{2}{*}{ Month } & \multicolumn{4}{|c|}{ Foam Tendency ASTM D 892, ml } \\
\hline & Turbine 1 & Turbine 2 & Turbine 3 & Turbine 4 \\
\hline 1 & 40 & 40 & 40 & 30 \\
\hline 2 & 40 & 40 & 40 & 30 \\
\hline 3 & 40 & 40 & 40 & 40 \\
\hline 4 & 40 & 40 & 40 & 40 \\
\hline 5 & 40 & 40 & 40 & 40 \\
\hline 6 & 40 & 40 & 40 & 40 \\
\hline 7 & 40 & 40 & 40 & 40 \\
\hline 8 & 45 & 50 & 45 & 45 \\
\hline 9 & 50 & 50 & 45 & 50 \\
\hline 10 & 50 & 50 & 50 & 50 \\
\hline 11 & 50 & 50 & 50 & 50 \\
\hline 12 & 50 & 50 & 50 & 50 \\
\hline 13 & 50 & 50 & 50 & 50 \\
\hline 14 & 60 & 60 & 60 & 60 \\
\hline 15 & 60 & 60 & 60 & 60 \\
\hline 16 & 65 & 60 & 60 & 65 \\
\hline 17 & 65 & 60 & 65 & 65 \\
\hline 18 & 70 & 65 & 70 & 70 \\
\hline 19 & 75 & 70 & 75 & 75 \\
\hline 20 & 80 & 75 & 80 & 80 \\
\hline 21 & 80 & 80 & 80 & 80 \\
\hline 22 & 85 & 85 & 85 & 90 \\
\hline 23 & 90 & 85 & 90 & 90 \\
\hline 24 & 95 & 90 & 90 & 95 \\
\hline 25 & 100 & 95 & 100 & 100 \\
\hline 26 & 100 & 100 & 100 & 100 \\
\hline 27 & 110 & 100 & 115 & 110 \\
\hline 28 & 120 & 120 & 120 & 120 \\
\hline 29 & 125 & 125 & 130 & 125 \\
\hline 30 & 145 & 140 & 150 & 145 \\
\hline 31 & 160 & 160 & 160 & 160 \\
\hline 32 & 180 & 180 & 180 & 170 \\
\hline 33 & 210 & 205 & 205 & 200 \\
\hline 34 & 235 & 235 & 240 & 235 \\
\hline 35 & 275 & 270 & 275 & 270 \\
\hline 36 & 320 & 310 & 320 & 320 \\
\hline 37 & 360 & 350 & 360 & 360 \\
\hline 38 & 400 & 400 & 395 & 400 \\
\hline
\end{tabular}

Based on the elements presented above, the mathematical model for the turbine oils lifetime prediction was developed, as is presented further.

The coefficients of the multiple regression mathematical model have been computed using MATLAB R2017b programming language. Among the functions this software offers, the fitlm function was chosen. The main reason for this choice was the possibility to make a variance analysis of the obtained results, proving that the model is reliable related to the experimental data, and can be successfully used in practice. 


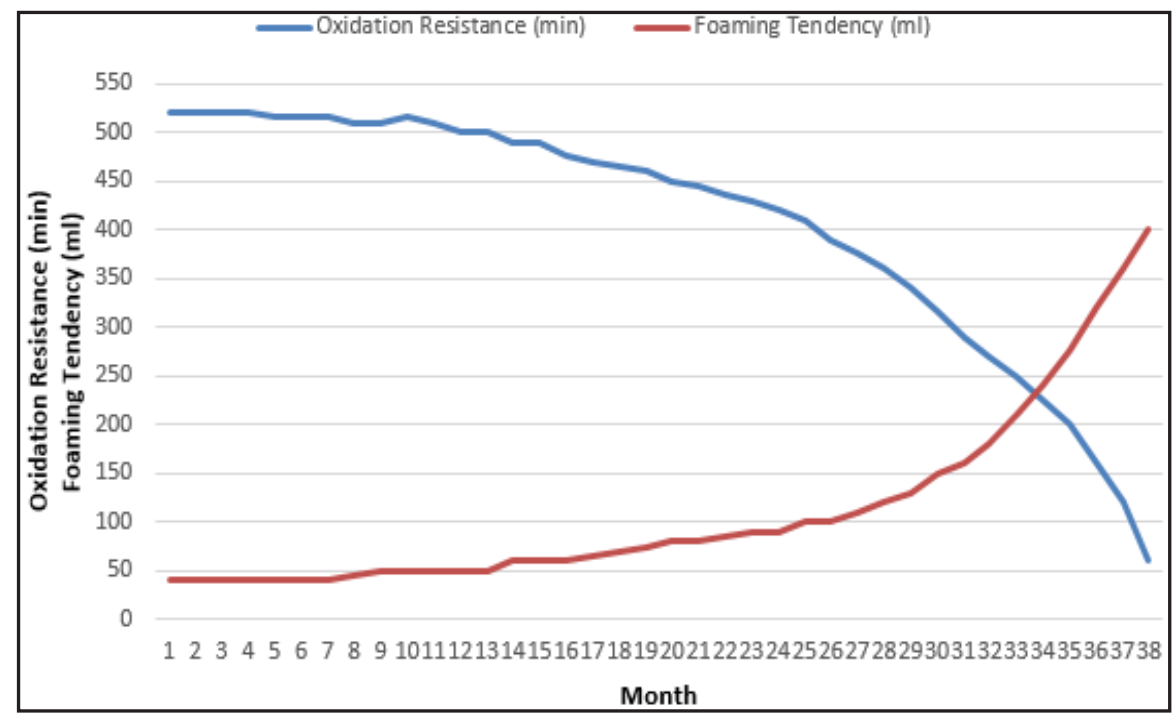

Fig. 1. Evolution of turbine oils oxidation resistance and foam tendency

Due to MATLAB is a C-based programming language, it also offers the possibility of having more than one syntax for the same function (feature called function overloading). All the functions and their syntaxes are very well documented [17]. The used syntax for fitlm function is: $\mathrm{mdl}=$ fitlm(X,y,modelspec $)$

The notations used in the above syntax are:

- mdl - a structure which contains the regression coefficients, along with other characteristics;

- X - matrix of independent variables;

- y - matrix of dependent variables;

- modelspec- the type of mathematical model for which its coefficients will be computed, called model specification. This parameter contains the names of the desired model specification. The names that will be used in this paper are presented in Table 4.

Due to there are more regression mathematical models made available by the fit $/ m$ subroutine, the procedure to determine the best fit will have the following steps:

-determine the coefficients for each of the mathematical regression models presented in Table 4;

-perform statistical analysis for each of the models determined at the previous steps;

-choose the bestmodel, based on the answers provided by the analysis.

If it is necessary, the fit/m procedure may suggest improvements of the chosen model specification, which are slight adjustments to the original model. Those suggestions will be considered as well.

The criterium chosen to determine the best model to use is the adjusted coefficient of determination $\left(R^{2}\right)$. The coefficient of determination indicates the proportional amount of variation in the dependent variable (known as response variable) explained by the independent variables in the linear regression model. The larger this coefficient is, the more variability is explained by the linear regression model.

The coefficient of determination is the proportion of the total sum of squares explained by the model. There are two types of this coefficient:
- ordinary (unadjusted) coefficient of determination; - adjusted coefficient of determination.

The ordinary coefficient of determination is computed using the following formula:

$$
R^{2}=1-\frac{S S E}{S S T}
$$

The notations in the above equation are:

$-R^{2}$ - the ordinary coefficient of determination;

-SSE- the sum of squared errors;

-SST- the sum of squared total.

The adjusted coefficient of determination, unlike the ordinary version, takes into account the number of coefficients of the mathematical model. It is computed using the formula:

$$
R^{2}=1-\left(\frac{n-1}{n-p}\right) *\left(\frac{S S E}{S S T}\right)
$$

The notations in equation ( 2 ) are:

- $\mathrm{R}^{2}$ - the adjusted coefficient of determination;

- $\mathrm{n}$ - the number of observations;

- $p$-the number of regression coefficients (including the intercept);

- SSE, SST - same meaning as in equation (1) [17].

Because the adjusted coefficient of determination considers the number of coefficients for the regression model, its value will always be lower than the value of the ordinary coefficient of determination. For the same reason, the adjusted coefficient was chosen as selection criteria, not its unadjusted counterpart.

\section{The constant model specification}

The general regression equation for the 'constant' definition name is:

$$
y=a_{0}
$$

The notations used in equation ( 3 ) are:

- $y$ - the dependent variable;

- $a_{\text {o }}$ - the model's intercept (constant);

As it can be noticed from equation (3), this model does not correlate the dependent and the independent variables. It only correlates the dependent variable with a constant

\begin{tabular}{|c|l|}
\hline Model specification & \multicolumn{1}{|c|}{ Model description } \\
\hline 'constant' & Model contains only a constant (intercept) term \\
\hline 'linear' & Model contains an intercept and linear terms for each predictor \\
\hline 'interactions' & $\begin{array}{l}\text { Model contains an intercept, linear terms, and all products of } \\
\text { pairs of distinct predictors (no squared terms) }\end{array}$ \\
\hline 'purequadratic' & Model contains an intercept, linear terms, and squared terms \\
\hline 'quadratic' & $\begin{array}{l}\text { Model contains an intercept, linear terms, interactions, and } \\
\text { squared terms }\end{array}$ \\
\hline
\end{tabular}

Table 4

MATHEMATICAL REGRESSION TYPESTHAT WILL BE USED THROUGHOUT THIS PAPER 
Table 5

THE OBTAINED MATHEMATICAL MODELS AND THEIR PERFORMANCES

\begin{tabular}{|c|c|c|}
\hline Model number & Model expression & $\begin{array}{c}\text { Adjusted } \\
R^{2}\end{array}$ \\
\hline $\begin{array}{c}\text { Does not } \\
\text { apply }\end{array}$ & 0.826 \\
\hline$(4)$ & $y=19.5$ & 0.903 \\
\hline$(6)$ & $y=52.041-0.079 * x_{1}$ & 0.932 \\
\hline$(8)$ & $y=60.708-0.11 * x_{1}-0.072 * x_{2}+0.0003 * x_{1} * x_{2}$ & 0.963 \\
\hline$(10)$ & $y=-28.833+0.422 * x_{1}-0.136 * x_{2}-0.0006 * x_{1}^{2}-0.0005 * x_{2}^{2}$ & 0.963 \\
\hline$(14)$ & $y=-268.27+1.303 * x_{1}+1.065 * x_{2}-0.002 * x_{1} * x_{2}-0.001 * x_{1}^{2}-0.0009$ & \\
\hline
\end{tabular}

(the intercept). The fitlm computed returned an intercept value of 19.5, so the mathematical model for the constant model specification is:

$$
y=19.5
$$

Because equation (4) does not depend on the independent variables, the $R^{2}$ value could notbe computed.

The same function suggested that equation (3) should be adjusted to equation (5):

$$
y=a_{0}+a_{1} * x_{1}
$$

From equation (5), the proposed model correlates the time only with the oxidation stability. The computed regression model is:

$$
y=52.041-0.079 * x_{1}
$$

The adjusted $R^{2}$ for equation (6) is 0.826 , which means that model (6) explains $82.6 \%$ of the variability in the dependent variables.

\section{The linear model specification}

The proposed model by the linear specification is:

$$
y=a_{0}+a_{1} * x_{1}+a_{2} * x_{2}
$$

Unlike previous models, model (7) takes both independent variables into account. The result returned by the fit/m function for model (7) is:

$$
y=122.521-0.205 * x_{1}-0.172 * x_{2}(8)
$$

The adjusted $R^{2}$ for model (8) is 0.903 , which means that model (8) explains $90.3 \%$ of the variability in the dependent variables.

Another proposed model, from the same category, is model (9):

$$
y=a_{0}+a_{1} * x_{1}+a_{2} * x_{2}+a_{3} * x_{1} * x_{2}
$$

The above model correlates not only the independent variables themselves, but also their product. The computed model is:

$y=60.708-0.11 * x_{1}-0.072 * x_{2}+0.0003 * x_{1} * x_{2}(10)$

The adjusted $R^{2}$ for model (10) is 0.932 which means that model (10) explains $93.2 \%$ of the variability in the dependent variables.

The interactions model specification. This model specification is identical with model (10) discussed above.

The purequadratic model specification. The proposed model for this kind of specification is:

$$
y=a_{0}+a_{1} * x_{1}+a_{2} * x_{2}+a_{3} * x_{1}^{2}+a_{4} * x_{2}^{2}(11)
$$

The notations from model (11) are the same as in the previous models from this paper.

Computing the model's coefficients using the fit/m function lead to the following result:

$$
\begin{gathered}
y=-28.833+0.422 * x_{1}-0.136 * x_{2}- \\
-0.0006 * x_{1}^{2}-0.0005 * x_{2}^{2}
\end{gathered}
$$

The adjusted $R^{2}$ for model (12) is 0.963 , which means that this model explains $96.3 \%$ of the variability in the dependent variables.

The quadratic model specification

The proposed model for this specification is:

$$
\begin{gathered}
y=a_{0}+a_{1} * x_{1}+a_{2} * x 2+a_{3} * x_{1} * x_{2}+ \\
+a_{4} * x_{1}^{2}+a_{5} * x_{2}^{2}
\end{gathered}
$$

The coefficients of model (13), computed by the function lead to the following model:

$$
\begin{gathered}
y=-268.27+1.303 * x_{1}+1.065 * x_{2}- \\
-0.002 * x_{1} * x_{2}-0.001 * x_{1}^{2}-0.0009 * x_{2}^{2}
\end{gathered}
$$

The adjusted $\mathrm{R}^{2}$ for this model is 0.963 , which means that this model explains $96.3 \%$ of the variability of the dependent variables.

The obtained mathematical models and their adjusted values are summarized in table 5 .

From table 5 , the more precise mathematical models are models (12) and (14) that are complex models and explain about $96 \%$ of the variability of the independent variables, which means that in about $96 \%$ of the cases, the model can be trusted. The models (4) and (6), with a value of adjusted $R^{2}$ of 0.826 , are not compatible with the purpose of the study. More specifically, for model (4), the values cannot be computed and obviously it cannot give accurate predictions, because the model does not depend on the two chosen dependent variables.

The results from this table are not surprising, because the more complex and elaborated models tend to be more accurate than their simpler counterparts. The novelty brought by this collaborative study, is the possibility to present a clear method to determine which mathematical model is more efficient and more appropriate.

The presented methods can be adjusted by the user, depending on the specific situations studied. The only drawback of the more complicated models is that it requires more computing power, because there are much more basic operations to be made.

\section{Conclusions}

The results and information resulted from the research and monitoring study of turbine oils behavior within 38 
months of service, allow formulating following conclusions:

- turbine oil quality monitoring is based on quality control programs that presume periodically testing of representative oils characteristics, which are influenced by the chemical degradation during the oils lifetime; when these characteristics exceed certain limits, the quality is affected and the operation of the equipment is no longer carried out under conditions of efficiency and safety. Estimating the evolution of some representative features of the oil and the time at which the oil needs to be replaced allows for a good lubrication management;

- the monitoring of the turbine oils, especially those which serves the turbine equipments of the energy plants, is very important in terms of efficiency and security because may prevent the occurrence of adverse events in the turbine operation and, also important, considering the significant large volumes and high cost of these oils;

- starting from the 38 months experimental testing, a mathematical modeling technique was developed in this study, in order to offer a better evaluation of the oil quality in real time and also to predict how many months are left before the lubricant change is required, until the properties will fall below the acceptable limits.

To use the obtained mathematical model to determine how much time is left until the oil needs to be replaced, the following steps are required:

- knowing the admissibility limits for the key characteristics (oxidation resistance and foaming tendency in this study case), the first step is to compute, using the determined mathematical model and the experimental results, after how many months of usage the oil will reach those limits;

- data concerning the oxidation resistance and foaming tendency for the studied oil, processed by a suitable mathematical model lead to predicting the degradation level of the oil and the remaining service life, at any given point in time.

- the model could be also designed using the evolution in time of other representative characteristics and could be extent for any type of lubricant.

\section{References}

1.SAHIL P., PETER R., VALERIE E., Applied Energy, Volume 93, May 2012, Pages 624-636.

2.DARKO LOVREC, VITO TIE, Determination and comparison between different hydraulic and turbine oils' lifetimes. 3rd Conference „Maintenance 2014, Zenica, B\&H, J une 11th - 13th, 2014, pag.153-160. 3.*** DIN 51515-1:2010-02, Lubricants and governor fluids for turbines Minimum requirements - Part 1: Turbine oils TD for normal service
4.*** DIN 51515-2: 2010-02 - Lubricants and governor fluids for turbines - Minimum requirements - Part 2: Turbine oils TG for high temperature service

5.*** GEK 28143A - General Electric Turbine oils standard

6.*** MAN Turbo SPD 10000494596 - Man Performance Features for turbine oils

7.LIGINGTONE, G., AMEYE, J., THOMPSON, B., Rethinking Condition Monitoring Strategies for Today's Turbine Oils, Machinery, Lubrication, Noria Corp, May/J une 2010.

8.SANDER, J., Steam Turbine Oil Challenges, Lubrication Engineers, 2012, http://www.lelubricants.com/lit/news/white\%20papers/ steam_turbine_oil_challenges.pdf

9.W. $\bar{F}$. BOW $\bar{M} A \bar{N}$, W., F., STACHOWIAK, G., W., Lubrication Engineering - LUBRIC ENG 01/1996; Volume 52(10):745-750.

10.W. F. BOW MAN, W., F., STACHOWIAK, G., W, Mechanical Engineering, Institution of Engineer, Australia, Vol.ME 23, No.1, 1998, pp 19-26.

11.K. PAPATZIMOS, A., DAWOOD, T., THIES, P.R. Cost-effective riskbased inspection planning for offshore wind farms (2018), Insight: Non-Destructive Testing and Condition Monitoring, Volume 60 (6), pp. 299-305.

12.BOGATU, L., Influence of chemical structure changing on lubricants behavior in service, Rev. Chim. (Bucharest), 65, no. 10, 2014, p. 12301234

13.BOGATU, L., ONUTU, I., CURSARU, D., New alternative for conditioned oils revaluation, Journal of the Balkan Tribological Association, 2015, Vol. 21, book 1, p.222-232, ISNN 1310-4772.

14.K. PAPATZIMOS, A., DAWOOD, T., THIES, P.R. Cost-effective riskbased inspection planning for offshore wind farms (2018), Insight: Non-Destructive Testing and Condition Monitoring, Vol. 60 (6), pp. 299-305.

15.NAGAR, A., MEHTA, S., Steam turbine lube oil system protections using SCADA \& PLC, Proceedings of the 2017 International Conference on Intelligent Computing and Control Systems, ICICCS 2017 Volume 2018-J anuary, 8 J anuary 2018, Pages 1376-1381.

16.MASDI, M1., MOHAMMADREZAT., B., ABDUL KARIM, Z., A., BANDAR, S., I., Methodology for short-term performance prognostic of gas turbine using recurrent neural netw ork, Proceedings of the 2015 International Conference on Industrial Engineering and Operations Management, Dubai, United Arab Emirates (UAE), March 3 - 5, 2015.

17.*** MathWorks Inc., MATLAB R2017b Help System. 2017.

18.***ASTM D 2272 - Standard Test Method for Oxidation Stability of Steam Turbine Oils by Rotating Pressure Vessel, Annual Book of ASTM Standards, Volume 05.01 Petroleum Products, Liquid Fuels, and Lubricants, 2011.

19.*** ASTM D 892 - Standard Test Method for Foaming Characteristics of Lubricating Oils, Annual Book of ASTM Standards, Volume 05.01 Petroleum Products, Liquid Fuels, and Lubricants, 2013

Manuscript received: 29.01 .2019 